\title{
Memerkenalkan Sejarah Pahlawan Nasional Ki Sarmidi Mangunsarkoro bagi Peserta Didik MI/SD di Indonesia
}

\author{
Septia Indah Cahyani ${ }^{1}$, Anis Fuadah $Z^{2}$ \\ 1,2 Program Magister Pendidikan Madrasab Ibtidaiyah, FITK UIN Jakarta \\ e-mail: septiaindh@gmail.com
}

\begin{abstract}
ABSTRAK. Behind the independence of the Indonesian State, many things are behind it. Education in Indonesia has existed since ancient times, to be precise in the pre-literacy era. Its development started from the pre-script era, the HinduBuddhist kingdom, and Islam until today. Ki Sarmidi Mangunsarkoro is an important factor in the field of education in Indonesia. The Minister of Teaching, Education and Culture, which he occupied, made many changes in Indonesia. The establishment of the Jakarta branch of Taman Siswa made children around them grow interested in reading and provided schools for children from underprivileged families. This study aims to improve students' enthusiasm for learning and to have a sense of struggle for education in Indonesia. The method that can be done is by looking for information about the history of Ki Sarmidi Mangunsarkoro from the history books of the Minister and the Indonesian Cabinet as well as the history books of Ki Sarmidi Mangunsarkoro. The results of this study show that students have a high enthusiasm for learning so that they can continue to the tertiary level and education in Indonesia becomes more advanced. Students have the nature of the view that education is very important. With the history of Ki Sarmidi Mangunsarkoro, there are a lot of knowledge of attitudes and morals that can be taken, one of which is educational.
\end{abstract}

Kata kunci: History, Policy, Ki Sarmidi Mangunsarkoro, Taman Siswa.

\section{PENDAHULUAN}

Indonesia merupakan negara yang berbentuk republik. Hal tersebut sudah diatur dalam UUD 1945 pasal 1 ayat 1 yang berbunyi "Negara Indonesia ialah Negara Kesatuan yang berbentuk republik." Untuk menjalankan sebuah pemerintahan di Indonesia, dibentuklah susunan tugas dalam negara. Indonesia mempunyai banyak kementerian, salah satunya Kementerian Pengajaran Pendidikan dan Kebudayaan yang biasa disingkat Kementerian PP dan K. Pada 14 Agustus 1949, Ki Sarmidi Mangunsarkoro menjabat sebagai Menteri. Jabatan sebagai Menteri Pendidikan itu dipangkunya saat masa kabinet Hatta yaitu Agustus 1949 - Januari 1950.

Berhubung dengan pendidikan, Indonesia merupakan salah satu negara yang sudah ada pelaksanaan pendidikan sejak zaman pra-aksara dan terus berlanjut hingga saat ini. Pada masa pra-aksara pelaksanaan pendidikan masih sangat sederhana dan berlangsung El-Ibtidaiy: Journal of Primary Education, Vol. 3, No. 2, Oktober 2020, Hal 154-167 
dalam lingkungan keluarga. Keluarga merupakan faktor utama dalam pendidikan seorang anak, karena saat anak lahir keluarga yang pertama kali yang dikenalnya. Saat zaman praaksara, pendidikan tersebut berupa ilmu mencari, mengelola dan mengolah makanan.

Pada masa kerajaan Hindu, Budha sampai Islam pendidikan disesuaikan dengan ajaran agama yang dianut dan pendidikan masa ini juga sangat tradisional. Pada zaman kerajaan Islam, pendidikan mengalami perkembangan melalui dibangunnya madrasah, kesenian, majlis ilmu dan sebagainya. Sedangkan pada masa penjajahan pendidikan di Indonesia yang diisi dengan pengajaran baca tulis untuk pemenuhan pegawai di pemerintahan demi kepentingan penjajah.

Perubahan zaman menunjukkan bahwa tujuan pendidikan memiliki kebutuhan yang berbeda. Sampai pada awal tahun 1950 tujuan pendidikan belum dirumuskan dalam suatu undang-undang yang mengatur pendidikan. Tujuan pendidikan hanya digariskan oleh Kementerian Pendidikan Pengajaran dan Kebudayaan dalm bentuk keputusan Menteri, 1 Maret 1946 yaitu warganegara sejati yang menyumbangkan tenaga dan pikiran untuk negara (Chairunnisa dan Zulkarnain, 2018).

Ki Sarmidi Mangunsarkoro selaku Menteri Pendidikan Pengajaran dan Kebudayaan memiliki peranan yang terbilang cukup besar. Ki Sarmidi Mangunsarkoro merupakan anak ketiga dari lima bersaudara dari pasangan Mangunsarkoro dan Eyang Wiryo Didjojo. Ki Sarmidi Mangunsarkoro berasal dari golongan Priyayi, namun golongan Priyayi Rendah. Karena ayahnya bekerja di dalam lingkungan keraton sebagai lurah yang mendapat gelar Ronggo.

Ki Sarmidi Mangunsarkoro lahir di Mangkoenegara, pada tanggal 23 Mei 1904 dan meninggal tanggal 8 Juni 1957 di Jakarta dan dimakamkan di Yogyakarta. Pendidikannya dimulai dari masuk pada usia 10 tahun di sekolah Angka Loro di Sawahan, Surakarta. Mata pelajaran yang diajari berupa menulis, membaca, berhitung, budi pekerti dan lain sebagainya. Kemudian melanjutkan ke sekolah Technische School Princes Juliana School. Tahun 1926, Ki Sarmidi Mangunsarkoro melanjutkan pendidikan ke Sekolah Guru Arjuna di Jakarta. Setelah tamat, Ki Sarmidi Mangunsarkoro melanjutkan ke perguruan tinggi Fakultas Hukum di Jakarta. Selain iu, ia juga aktif dalam organisasi.

Pada tahun 1928, Ki Sarmidi Mangunsarkoro aktif bergabung dalam Partai Nasional Indonesia dan aktif dalam organisasi Partindo, Gerindo, dan Serindo. Ia juga pernah menjabat sebagai Ketua Departemen Pendidikan dan Pengajaran Majelis Luhur Taman Siswa. Setelah lulus dari Sekolah Guru Arjuna pada tahun 1926, pada saat itulah dirinya masuk ke lingkungan Taman Siswa. Ki Sarmidi Mangunsarkoro kembali ke Yogyakarta untuk menjadi guru di Taman Siswa Yogyakarta (Dwi \& Yahya, 1957).

Berjalan satu tahun, tepat pada tanggal 24 Agustus $1929 \mathrm{Ki}$ Sarmidi Mangunsarkoro menikahi seorang gadis cantik yang bernama Sri Wulandari. Sri Wulandari juga salah satu faktor penting dalam perkembangan pendidikan di Indonesia. Sri Wulandari lahir pada tanggal 16 Mei 1905 di Madiun. Semenjak menikah dengan Ki Sarmidi Mangunsarkoro namanya berubah mengikuti nama suaminya yaitu Sri Mangunsarkoro. Hingga saat ini beliau dikenal dengan Nyi Mangunsarkoro.

Pernikahannya menjadi istimewa karena Ki Hajar Dewantara berkenan menjadi salah satu wali nikah. Keluarga Sarmidi mengalami suka dan duka. Suka apabila segala apa yang dicita-citakan kedua pasangan hidup ini tentang organisasi Taman Siswa berjalan 
sesuai dengan yang dicita-citakan Ki Hajar Dewantara, sedangkan duka yaitu jika melihat dan mendengar bahwa rasa nasionalisme dalam pendidikan menurun.

Sebelum menjadi Menteri PP dan K, Sarmidi mendirikan Akademi Seni Rupa Indonesia (ASRI) di Yogyakarta. Ki Sarmidi Mangunsarkoro adalah salah satu orang yang sangat berperan penting dalam pendidikan di Indonesia. Saat dirinya diangkat menjadi Menteri Pendidikan, banyak kebijakan yang diterapkannya. Kebijakan-kebijakan yang ia ambil didasarkan pada realitas yang terjadi pendidikan di Indonesia (Chairunnisa dan Zulkarnain, 2018).

Dengan mempunyai latar belakang dalam pendidikan, Ki Sarmidi Mangunsarkoro sudah sangat mengerti untuk mengatasi permasalahan pendidikan di Indonesia. Sebagai Menteri, peranan Sarmidi dalam dunia pendidikan di Indonesia bisa dibilang cukup besar. Selain itu, Sarmidi mempunyai banyak karya-karya tulis baik dalam bentuk buku maupun majalah. Salah satu tulisan Ki Sarmidi Mangunsarkoro berjudul "Pendidikan Nasional dan Pendidikan Baru di Indonesia." Karya tulis tersebut cukup terkenal di kalangan masyarakat karena memiliki pengaruh besar terhadap pendidikan di Indonesia.

Sebelum mendirikan Taman Siswa cabang Jakarta, tahun 1932 Perguruan Taman Siswa di Yogyakarta melahirkan sejumlah tokoh seperti Ki Sarmidi Mangunsarkoro (Menteri PP dan K) dan Amin saelan (tokoh pejuang dari Makassar). Akhirnya, ia mendirikan sebuah tempat belajar bagi anak-anak yaitu Taman Siswa di Jakarta (Psikologi \& Jaya, 2016). Ki Hajar Dewantara selaku pendiri Taman Siswa di Yogyakarta, meminta Ki Sarmidi Mangunsarkoro untuk mendirikan Taman Siswa cabang Jakarta yang bertempat di Jalan Garuda No. 71 Kemayoran. Perguruan Taman Siswa cabang Jakarta adalah gabungan HIS Budi Utomo dan HIS Marsudi Rukun yang keduanya dipimpin oleh Ki Sarmdi. Berdirinya Taman Siswa cabang Jakarta, masyarakat Kemayoran sangat antusias dengan cara menyambutnya dengan sangat baik. Dan Taman Siswa ini mengalami kemajuan yang sangat pesat (Dwi \& Yahya, 1957).

Gelar "Ki" yang ada di di depan nama Sarmidi didapatkan sejak ia mengajar di Taman Siswa Yogyakarta. Taman Siswa Jakarta terdiri atas Taman Kanak-kanak (Taman Indriya) dan Taman Muda, kemudian pada 1931 dibuka pula Taman Dewasa (SMP). Pada tahun 1933, Taman Dewasa berkembang menjadi Taman Dewasa Raya (Sekolah Menengah Lima Tahun), setingkat dengan Hoogere Burgerschool (HBS), dengan semboyan "Menuju Masyarakat dan Sekolah Tinggi Nasional" sekaligus sebagai persiapan Perguruan Tinggi Kebangsaan.

Taman Siswa Jakarta yang pada awalnya kecil akhirnya kebanjiran murid baik di TK, Taman Muda, Taman Dewasa maupun di Taman Dewasa Raya sebagai persiapan perguruan tinggi kebangsaan. Guru yang mengajar Taman Siswa diperbolehkan mengikuti organisasi politik akan tetapi dilarang keras membawa politik ke ruang sekolah. Selain itu, Ki Sarmidi Mangunsarkoro merupakan penyusun daftar pelajaran di Taman Muda. Taman Muda merupakan Perguruan Taman Siswa menggunakan metode kesenian antara lain gerak badan (permainan anakdan tari dasar), menggambar, dan menyanyi. Ki Sarmidi Mangunsarkoro selaku ketua Taman Siswa Jakarta menjelaskan bahwa cara memberikan pengajaran kesusilaan dan keindahan dapat dilakukan di dalam ruangan, kebun, atau tempat lainyang dapat menambah terbukanya jiwa anak untuk menerima pelajaran (Tarigan, 2013). 
Selama menjadi Menteri Pendidikan, persentase angka buta huruf di kalangan masyarakat terutama anak-anak masih sangat tinggi. Oleh sebab itu, beliau mengeluarkan salah satu kebijakannya yaitu Pemberantasan Buta Huruf (PBH) dengan mengadakan kursus-kursus PBH. Selain itu, beliau menggratiskan biaya sekolah dasar atau SD agar semuanya dapat bersekolah yang berdampingan dengan kebijakan $\mathrm{PBH}$ tersebut. Masa jabatan Ki Sarmidi Mangunsarkoro berakhir pada tanggal 6 September 1950. Walaupun begitu, ia tetap aktif dalam organisasi yaitu diangkat secara resmi untuk membentuk Kabinet Nasional oleh presiden Republik Indonesia (Chairunnisa dan Zulkarnain, 2018).

Tepat pada hari Selasa tanggal 4 Juni 1957, Ki Sarmidi Mangunsarkoro menjalani perawatan di rumah sakit CBS Jakarta karena kondisi tubuhnya kurang sehat untuk beberapa hari sebelumnya. Setelah dilakukan pemeriksaan, Ki Sarmidi Mangunsarkoro dinyatakan menderita Influenza Verdaag Thypus, dan Herzen Vlis Onsteking yang menyebabkan dirinya panas tinggi hingga 47 derajat celcius. Pada hari Sabtu, pukul 10.10 WIB, tanggal 8 Juni 1957 Ki Sarmidi Mangunsarkoro meninggal dunia yang membuat warga Indonesia berduka dan kehilangan salah satu tokoh pendidikan dan pejuang kemerdekaan (Dwi \& Yahya, 1957).

\section{METODOLOGI}

Metode yang digunakan dalam penelitian ini adalah library research atau studi pustaka. Pendekatan kepustakaan atau studi pustaka merupakan serangkaian kegiatan yang meliputi pengumpulan data pustaka, membaca, mencatat, dan mengolah bahan penelitian. Studi pustaka atau library research adalah penelitian yang dilakukan oleh peneliti dengan mengumpulkan sejumlah buku-buku, majalah, liflet, yang berkaitan dengan masalah dan tujuan penelitian (Iii, 2005).

Metode ini tidak memerlukan untuk terjun langsung mengobservasi dengan sumber. Dengan studi pustaka, peneliti akan menganalisis data yang dibuat melalui membaca dan mencatatat. Selain itu, peneliti dapat menganalisis tulisan dengan membandingkan karyakarya tulisan orang lain. Metode yang digunakan memang terlihat sangat mudah, akan tetapi peneliti butuh ketekunan dalam mengumpulkan data, membaca, mencatat serta mengolah data dari banyaknya referensi. Referensi yang digunakan oleh peneliti dari berbagai sumber seperti buku, artikel jurnal, maupun karya tulis lainnya. Metode ini tidak menghabiskan waktu cepat akan tetapi lama karena peneliti harus benar-benar memahami isi dari referensi yang menjadi sumber data. Dalam proses menulis artikel ini, penulis mengumpulkan seluruh data yang berkaitan dengan tema bahasan yaitu sejarah Ki Sarmidi Mangunsarkoro bagi peserta didik MI/SD. Setelah, peneliti memiliki sumber yang cukup, peneliti membaca secara mendalam, menganalisis data dari semua referensi yang terpercaya dan mendiskusikan hasil yang diperoleh serta meringkasnya menjadi sebuah kumpulan data yang singkat. 


\section{HASIL DAN PEMBAHASAN}

\section{Riwayat Hidup Ki Sarmidi Mangunsarkoro}

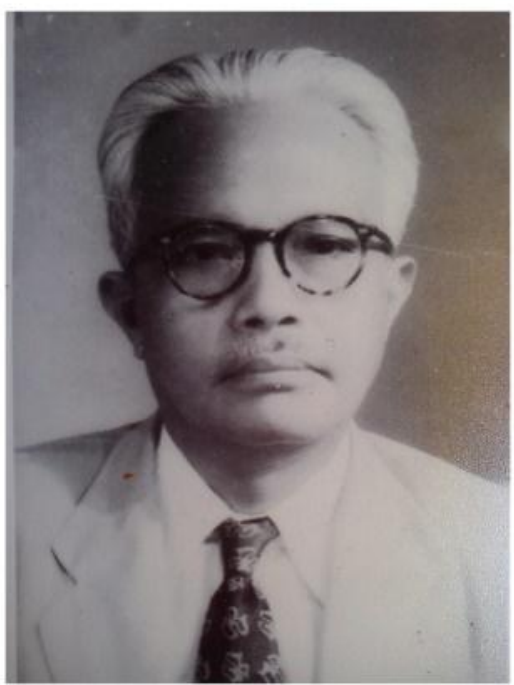

\section{Gambar 1 Ki Sarmidi Mangunsarkoro}

Ki Sarmidi Mangunsarkoro lahir pada tanggal 23 Mei 1904 di Desa Banyuanyar, Colomadu, Surakarta, Jawa Tengah. Nama Mangunsarkoro yang terletak pada akhir namanya, yaitu diambil dari nama ayahnya Mangunsarkoro. Ki Sarmidi Mangunsarkoro merupakan anak ketiga dari lima bersaudara dari pasangan Mangunsarkoro dan Eyang Wiryo Didjojo. Menjadi anak ketiga dari lima bersaudara, Ki Sarmidi memiliki saudara pertama pernama Prowirosugito, saudara keduanya bernama Saryadi, saudara yang ketiga bernama Sarsami, dan saudara keempat bernama Suryati.

Ki Sarmidi Mangunsarkoro berasal dari keluarga golongan priyayi rendah. Ayahnya seorang abdi dalem Keraton Surakarta dengan gelar "Ronggo", sehingga namanya Ronggo Mangunsarkoro. Gelar yang didapat ayahnya karena sebagai pejabat yang memimpin suatu daerah setingkat desa untuk mengelola tanah dan hasil buminya kemudian disetorkan ke keraton. Nama Mangunsarkoro terdiri dari dua kata, yaitu mangun yang berarti mengelola dan sarkoro yang berarti gula. Dengan demikian, Desa Banyuanyar yang ditempatinya merupakan salah satu wilayah penghasil gula (Tarigan, 2013).

Tepat pada tanggal 24 Agustus 1929 merupakan hari yang sangat istimewa bagi Ki Sardimi. Ki Sarmidi Mangunsarkoro menemukan jodohnya lalu menikahi seorang gadis cantik yang bernama Sri Wulandari. Pernikahannya menjadi sangat istimewa dikarenakan Ki Hajar Dewantara berkenan menjadi salah satu wali nikah. Dari pernikahannya itu mereka memiliki delapan orang anak. Delapan orang anaknya tersebut yaitu (1) sepasang anak kembar, tetapi meninggal saat dilahirkan; (2) Nusawardhani Mangunsarkoro; (3) Dharmakirti Mangunsarkoro; (4) Artha Wardani Mangunsarkoro; (5) Wiyata Wardhani Mangunsarkoro; (6) Yudhasta Mangunsarkor; (7) Budhi Wardhani Mangunsarkoro (Rh. Widada, 2013).

Sri Wulandari merupakan salah satu faktor penting dalam perkembangan pendidikn di Indonesia. Sri Wulandari lahir pada tanggal 16 Mei 1905 di Madiun. Semenjak menikah dengan Ki Sarmidi namanya berubah mengikuti nama suaminya yaitu Sri Mangunsarkoro. Hingga saat ini beliau dikenal dengan Nyi Sarmidi. 
Hingga tiba ajalnya, tepat pada hari Sabtu, 8 Juni 1957 pukul 10.10 WIB beliau menutup usia di Rumah Sakit CBS Jakarta. Kematian sosok tokoh penting di Indonesia membuat rakyat Indonesia berduka karena kehilangan tokoh pendidikan yang sangat berperan penting di Indonesia. Sebelum meninggal, Ki Sarmidi mengidap penyakit Influenza Verdaag Thypus, dan Herzen V lis Onsteking yang menyebabkan dirinya panas tinggi hingga 47 derajat celcius. Dikarenakan tubuhnya yang tak dapat menahan kuat penyakit itu akhinya beliau menutup usia (Dwi \& Yahya, 1957).

\section{Pendidikan Ki Sarmidi Mangunsarkoro}

Dengan jabatan yang dimilikinya ayahnya, Sarmidi memiliki nasib yang lebih baik daripada anak-anak lain di desanya. Pada umur 10 tahun ia masuk ke Sekolah Angka Loro di Sawahan, Surakarta. Pelajaran yang diajarkan di Sekolah Angka Loro yaitu membaca, menulis, berhitung, olahraga, bernyanyi, mendongeng, budi pekerti dan pelajaran tambahan bahasa jawa. Setelah tamat 2 tahun di Sekolah Angka Loro, beliau melanjutkan pendidikan di Sekolah Teknik Princes Juliana di Yogyakarta.

Sekolah Teknik Princes Juliana merupakan sekolah pada jenjang SMP. Walaupun bukan sesuai minat dan bakatnya di bidang teknik, beliau tetap menjalani pendidikannya hingga tamat. Ki Sarmidi cenderung mempelajari ilmu di luar bidang teknik tersebut, seperti ilmu pendidikan dan psikologi. Beliaupun bergabung dalam komunitas Islam Studie Club di sekolah tersebut.

Setelah lulus Sekolah Teknik Princes Juliana, beliau merantau ke Jakarta untuk melanjutkan pendidikannya di sana. Di Jakarta, beliau melanjutkan pendidikan di Sekolah Guru Arjuna. Setelah memilih Sekolah Guru Arjuna, membuat Ki Sarmidi harus pindah ke Jakarta dan meninggalkan daerah asalnya yaitu Yogyakarta. Sekolah Guru Arjuna yang didudukinya ini merupakan sekolah yang setara dengan jenjang SMA. Kepindahannya ke Jakarta membuat dirinya dekat dengan kegiatan pergerakan.

Pada tahun 1932, Ki Sarmidi melanjutkan ke tingkat perguruan tinggi di Fakultas Hukum Jakarta untuk mendalami ilmu pendidikannya dalam menguasai ilmu-ilmu sosiologi. Dikarenakan kesungguhannya di bidang ilmu sosiologi, beliau berhasil membuktikannya dengan menerbitkan karyanya di bidang ilmu sosiologi (Dwi \& Yahya, 1957).

\section{Taman Siswa Jakarta}

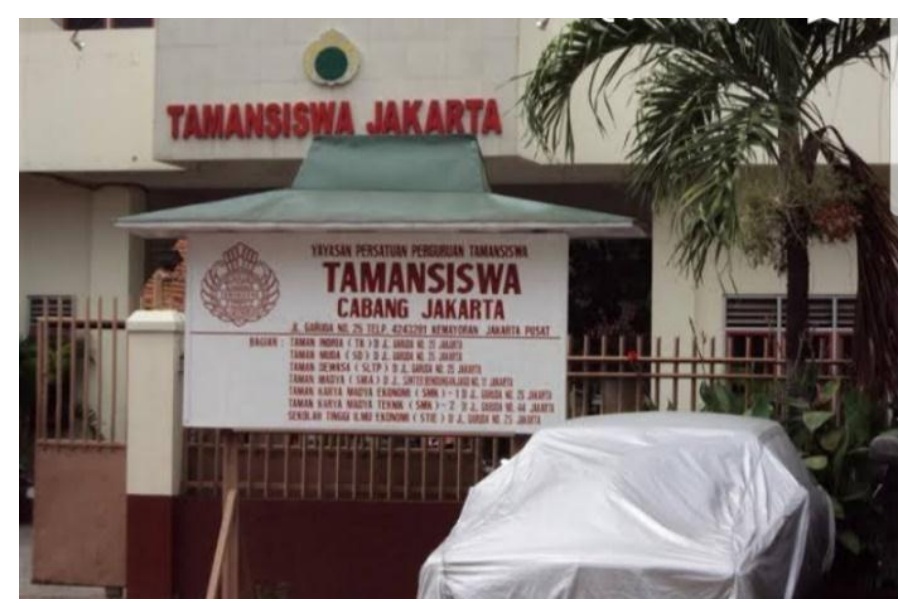

Gambar 2 Taman Siswa Jakarta 
Sebelum mendirikan sebuah perguruan Taman Siswa Jakarta, Ki Sarmidi mengabdi di Taman Siswa Yogyakarta. Setelah tamat pendidikannya di Sekolah Guru Arjuna pada tahun 1926, Ki Sarmidi pulang ke Yogyakarta untuk mengabdi menjadi guru di Taman Muda Taman Siswa Yogyakarta. Oleh karena itu, gelar "Ki” yang didapatnya ketika ia mengajar di sana. Selama tiga tahun beliau mengajar di sana.

Pada tahun 1929, Ki Sarmidi kembali ke Jakarta. Selama di Jakarta, Ki Sarmidi diangkat sebagai kepala sekolah HIS Budi Utomo dan kemudian juga menjadi kepala sekolah HIS Marsidi Rukun. Kedua sekolah tersebut merupakan cikal bakal terdirinya Taman Siswa Jakarta. Dikarenakan sebagai kepala sekolah, akhirnya Ki Sarmidi menggabungkan HIS Budi Utomo dan HIS Marsudi Rukun (Tarigan, 2013).

Pembelajaran di Taman Siswa Yogyakarta tempat Ki Sarmidi Mangunsarkoro mengabdi menggunakan landasan metode sistem "among". Metode "among" ini berlandaskan kekeluargaan. Selain itu, pembelajaran pada Taman Siswa Yogyakarta dengan membentuk swa-disiplin melalui Tut Wuri Handayani, prinsip keteladanan Ing Ngarsa Tuladha, serta membangun kemauan belajar melalui Ing Madya Mangun Karsa.

Pembentukan Swa-disiplin Tut Wuri Handayani memiliki makna mendukung anak didik dari belakang. Maksudnya adalah pendidik memberi motivasi dan dorongan kepada anak didik dari belakang. Ing Ngarsa Tuladha memiliki makna seseorang harus menjadi contoh dan menjadi teladan yang positif di segala bidang, misalnya seorang pemimpin harus menjadi contoh bagi anak buahnya kemudian pendidik harus menjadi contoh bagi anak didiknya. Ing Madya Mangun Karsa memiliki makna pendidik membina pengikut/anak dengan membangun kemauan anak didik agar lebih aktif (Psikologi \& Jaya, 2016).

Ki Sarmidi yang merupakan salah satu pemimpin Taman Siswa menyebutkan 7 pasal asas Taman Siswa merupakan bahwa asas itu sebagai lanjutan cita-cita Ki Hajar Dewantara dan kawan-kawannya yang tergabung dalam Geromboloan Selasa Kliwon, sebagai anak rohani gerakan politik kiri dan gerakan kebatinan yang menganjurkan kebebasan. Tujuh pasal asas Taman Siswa itu adalah (1) pasal 1 dan 2 mengandung dasar kemerdekaan tiap orang terhadap dirinya sendiri; (2) pasal 3 mengandung menyinggung kepentingan-kepentingan sosial, politik, dan ekonomi; (3) pasal 4 mengandung dasar kerakyatan; (4) pasal 5 mengandung percaya kepada kekuatan diri sendiri untuk tumbuh dan berkembang; (5) pasal 6 mengandung persyaratan dalam mengejar kemerdekaan diri; dan (6) pasal 7 mengandung adanya keikhlasan lahir batin bagi guru untuk mendekati anak didiknya (Anisah et al., 2015).

Pembangunan Perguruan Taman Siswa Jakarta merupakan permintaan masyarakat kemayoran dan restu Ki Hajar Dewantara. Akhirnya, Ki Sarmidi memutuskan untuk mendirikan Perguruan Taman Siswa di Jakarta pada 14 juli 1929. Dana awal yang dikeluarkan untuk mendirikan perguruan ini sebesar 500 gulden. Perguruan ini terletak di Jalan Garuda No. 71 Kemayoran. 


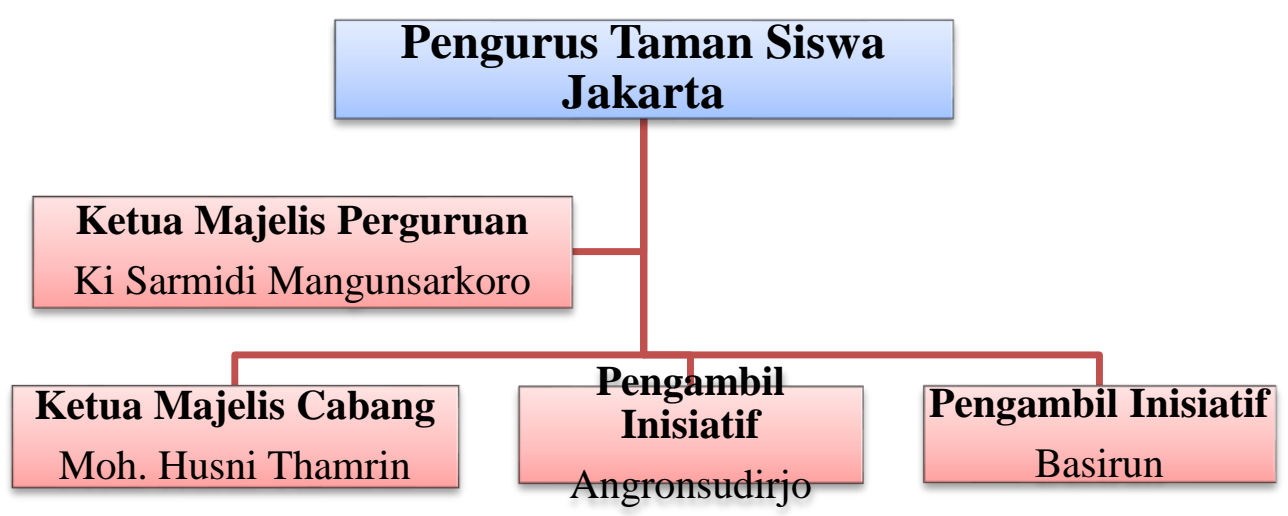

\section{Gambar 3 Bagan Kepengurusan Perguruan Taman Siswa Jakarta}

Dalam mendirikan perguruan ini, Ki Sarmidi bekerja sama dengan Moh. Husni Thamrin yang merupakan seorang tokoh masyarakat Betawi. Setelah pembangunan selesai, Moh. Husni Thamrin dalam kepengurusan Perguruan Taman Siswa bertindak sebagai Ketua Majelis Cabang dan Ki Sarmidi Mangunsarkoro sebagai pendiri sekaligus Ketua Majelis Perguruan. Selain itu, Angronsudirjo dan Basirun yang merupakan masyarakat kemayoran bertindak sebagai Pengambil Inisiatif pendirian Taman Siswa.

Perguruan Taman Siswa Jakarta ini dibangun saat Indonesia masih dijajah oleh Pemerintahan Hindia-Belanda. Perguruan Taman Siswa membawa manfaat besar bagi masyarakat sekitar. Mereka yang tidak dapat menyekolahkan anak-anaknya ke sekolah Belanda karena tidak memenuhi kriteria yang ditetapkan, akhirnya mereka menyekolahkannya di Perguruan Taman Siswa. Taman Siswa mempunyai paham bahwa pendidikan merupakan sarana untuk memerdekakan manusia. Oleh karena itu, perguruan ini sangat menerima dengan senang hati jika ada anak yang ingin sekali belajar.

Selama proses perkembangan Taman Siswa ternyata dipandang berbahaya oleh Pemerintah Hindia-Belanda. Oleh sebab itu, pemerintah colonial berupaya merintangi agar proses perkembangannya terhambat dengan mengeluarkan Ordanansi Sekolah Liar pada 01 Oktober 1932. Perarturan yang ditetapkan yaitu (1) pendirian sekolah partikelir harus meminta izin kepada Pemerintah Hindia-Belanda; (2) sebelum mengajar guru sekolah partikelir harus meminta izin mengajar terlebih dahulu dari pemerintah. Berdasarkan peraturan tersebut, Perguruan Taman Siswa salah satunya yang digolongkan sebagai sekolah liar. Akan tetapi, berkat kegigihan memperjuangkan hak untuk tetap berdiri, ditambah dengan dukungan sebagian besar siswa dan orang tua mereka, Ordonasi tersebut dicabut (Rh. Widada, 2013).

Tamansiswa Jakarta yang semulanya kecil, kemudian mulai berkembang dan memiliki banyak murid-murid. Perkembangan Taman siswa ini menarik perhatian masyarakat Indonesia karena Sarmidi Mangunsarkoro sangat pandai dalam mendekati rakyat dan diinginkan murid-murid dari semua tingkatan. Sri Mangunsarkoro istri dari Ki Sarmidi Mangunsarkoro menjadi ketua Taman Anak Tamansiswa Yogyakarta mulai tahun 1925. Saat ini, Sri Mangunsarkoro lebih berfokus pada pendidikan untuk anak-anak. Berawal dari sebagai pamong Tamansiswa kemudian sekarang dijadikan ketua Taman Anak (Putri \& Dyah, 2016).

Perguruan Taman Siswa Cabang Jakarta itu terus berkembang. Awalnya hanya untuk Taman Anak (Taman Indiria) dan Kursus Guru, kemudian bertambah dengan 
adanya Taman Muda yang diperuntukkan jejang SD kelas IV sampai kelas VI. Selain itu, Taman Dewasa yang diperuntukkan jenjang SMA Taman Siswa. Oleh karena itu, perguruan ini berupaya memperluas lahan dan menambah gedung sekolah. Pada tahun 1933, Perguruan Taman Siswa Jakarta menambah banyak tingkatan pendidikannya yaitu dengan membuka Taman Dewasa Raya (TDR, setingkat SMA) sebagai kelanjutan Taman Dewasa yang telah ada. Semangat yang dibangun di TDR yaitu "Menuju Masyarakat dan Sekolah Tinggi Nasional" (Rh. Widada, 2013).

Tamansiswa Jakarta yang semulanya kecil, kemudian mulai berkembang dan memiliki banyak murid-murid. Hal tersebut menarik perhatian masyarakat Indonesia karena memang Sarmidi Mangunsarkoro pandai dalam mendekati rakyat dan diminati murid-murid dari semua tingkatan. Setelah sekian lama memimpin perguruan ini, Ki Sarmidi Mangunsarkoro mempunyai tugas yang harus diselesaikan yaitu menyusun sebuah Daftar Pelajaran Baru. Tugas ini dikerjakan oleh beliau melalui konferensi para pemimpin Taman Siswa. Daftar Pelajaran Baru ini menekankan penggunaan Bahasa Indonesia daripada Bahasa Belanda sebagai pengantar dalam pelajaran.

Secara sadar dengan adanya penekanan pada Bahasa Indonesia Taman Siswa mengikuti semangat Sumpag Pemuda 1928. Tugas tersebut dilaksanakan dengan sebaik mungkin oleh Ki Sarmidi Mangunsarkoro. Pada tahun 1932, rancangan itu disahkan dalam suatu kongres dan diberi nama "Daftar Pelajaran Mangunsarkoro". Oleh karena itu, Ki Sarmidi menulis banyak buku salah satunya yang berjudul "Pengantar Guru Nasional". Buku tersebut mengalami cetak ulang pada tahun 1935. "Daftar Pelajaran Mangunsarkoro" merupakan rancangan yang mencerminkan cita-cita Taman Siswa dan buku "Pengantar Guru Nasional" memiliki arti penting yaitu pemikiran yang terkandung di dalamnya aspek kebangkitan nasionalisme (Rh. Widada, 2013).

Penyusun daftar pelajaran di Taman Muda antara lain Soewandhie dan Ki Sarmidi Mangunsarkoro. Rencana daftar pelajaran yang disusun oleh Soewandhie mendapatkan sedikit perubahan pada tanggal 17-23 Desember 1933. Kemudian, penyusunan rencana atau daftar pelajaran Taman Dewasa diserahkan kepada Perguruan Tamansiswa Jakarta setelah adanya Rapat Besar tahun 1933. Ki Sarmidi Mangunsarkoro (Ketua Taman Siswa Jakarta) menjelaskan bahwa cara memberikan pengajaran kesusilaan dan keindahan dapat dilakukan di dalam ruangan, kebun, atau tempat lain yang dapat menambah terbukanya jiwa anak untuk menerima pelajaran (Reza dan Dyah, 2018).

\section{Organisasi}

Ki Sarmidi menjadi anggota Trikoro Dharmo pada usia 19 Tahun, saat a sedang duduk di Sekolah Teknik PJS Yogyakarta. Trikoro Dharmo (TKD) merupakan perhimpunan pemuda pelajar Indonesia yang pertama di zaman penjajahan. TKD secara harfiah tiga tujuan mulia berdiri di Betawi (Jakarta) pada 7 Maret 1915 di gedung pertemuan Budi Utomo. Trikoro Dharmo diketuai oleh mahasiswa sekolah dokter yaitu Satiman Wirjosandjojo.

Tiga tujuan mulia tersebut yaitu (1) menanamkan ras cinta tanah air; (2) melatih para calon pemimpin nasional; (3) mempertebal persaudaraan antar suku-suku bangsa di Indonesia. Tepat pada 12 Juni 1918, nama TKD diubah menjadi Jong Java (JJ) dengan dasar organisasi kebudayaan Jawa Raya di Solo. Di Jong Java Yogyakarta, Ki Sarmidi 
Mangunsarkoro merupakan salah seorang yang menganjurkan gagasan tentang kesatuan Indonesia (Rh. Widada, 2013).

Pada tahun 1922, ia bergabung dengan organisasi Jong Java di Yogyakarta. Ki Sarmidi memimpin majalah terbitan Jong Java yaitu Soeara Afdeling Djogja, bahkan pada tahun 1926 ia terpilih sebagai Ketua Jong Java lalu menjadi Ketua Jong Theosofien Yogyakarta. Dan pada tahun 1927, ia semakin serius mendalami ilmu pendidikan di Dreijarige Normalcursus Djogjakarta (Tarigan, 2013). Selain ilmu pendidikan yang ditekuninya, Ki Sarmidi Mangunsarkoro juga getol mengambil peran dalam pergerakan kebangsaan yang dipelopori oleh kaum muda. Puncak pergerakan itu terjadi pada momen Sumpah Pemuda tahun 1928. Organisasi pemuda yang bergabung antara lain yaitu Jong Java, Jong Sumatera, Jong Batak, Jong Minahasa, Jong Ambon, dan sebagainya. Akhirnya, berdirilah organisasi pemuda yang bernama Pemuda Indonesia (PI). PI semua bernama Jong Indonesia yang didirikan di Bandung pada 1927.

Ki Sarmidi yang telah aktif di Jong Java cabang Yogyakarta tentu menyambut dengan penuh semangat kelahiran Pergerakan Pemuda Indonesia. Saat Pemuda Indonesia berniat membuat cabang di Yogyakarta, Ki Sarmidi Mangunsarkor sebagai pemimpin Jong Java dengan senang hati mendukungnya. Akhirnya, berdirilah Pemuda Indonesia cabang Yogyakarta dengan Ki Sarmidi Mangunsarkoro sebagai salah satu pendirinya. Sejak bergabung dengan Pemuda Indonesia, ia gencar menyusun gagasan tentang fusi atau peleburan berbagai gerakan pemuda. Tepat pada 28 Oktober 1928 hari Sumpah Pemuda, dalam peristiwa besar ini $\mathrm{Ki}$ Sarmidi dipercaya untuk tampil membawakan gagasangagasannya dalam bidang pendidikan. Selain itu, Ki Sarmidi Mangunsarkoro bergabung pada pergerakan nasional yang bernama Perserikatan Nasional Indonesia pada 4 Juli 1927. Alasan ia bergabung dengan pergerakan tersebut karena adanya dorongan dalam dirinya untuk menyalurkan gagasan tentang kesatuan dan persatuan serta kemerdekaan bangsa secara lebih khusus dan lugas.

Berjalan satu tahun kemudian, Perserikatan Nasional Indonesia berubah namanya menjadi Partai Nasional Indonesia (PNI). Sebagai anggota PNI, Ki Sarmidi Mangunsarkoro mendukung apa yang telah menjadi tujuan dan garis perjuangan partai. Partai Nasional Indonesia (PNI) bertujuan untuk mencapai Indonesia merdeka dan terlepas dari segala penjajahan. Tujuan tersebut bisa diraih jika Indonesia mampu berdiri sendiri atau percaya pada diri sendiri dan tidak bekerja sama dengan pemerintah kolonial Belanda. Lalu, PNI bubar dan didirikan Partai Indonesia (Partindo) sebagai penerusnya. Walaupun PNI bubar, Ki Sarmidi Mangunsarkoro tetap aktif di dalamnya. Bahkan di dalam Partindo jiwa nasionalisme semakin menguat (Rh. Widada, 2013).

\section{Menteri Pendidikan, Pengajaran dan Keterampilan Indonesia}

Peranan Ki Sarmidi Mangunsarkoro pada aspek pendidikan saat awal kemerekaan salah satunya adalah menjadi Menteri Pendidikan pada tahun 1949-1950. Jabatan yang digenggamnya ini hanya berjalan satu tahun. Selain itu, menggenggam jabatan Menteri Pendidikan itu dipangkunya pada periode kabinet Hatta yaitu Agustus 1949 - Januari 1950 dan pada periode kabinet Halim yaitu Januari 1950 - September 1950 bagi RI yang saat itu masih menjadi negara bagian Republik Indonesia Serikat (RIS) (Guntur \& Zulkarnain, 2016). 
Ki Sarmidi Mangunsarkoro dalam sejarah perjalan bangsa Indonesia merupakan Menteri PP dan K yang ke tujuh menggantikan Mr. Tengku Mohamad Hasan. Saat diangkat menjadi menteri, Ki Sarmidi tidak seperti menteri lain yang segera pindah ke rumah dinas, akan tetapi keluarganya tetap tinggal di rumahnya yang sangat sederhana. Hal itu disebabkan, Ki Sarmidi Mangunsarkoro mempunyai pendapat bahwa jika suatu saat nanti kabinet jatuh dan tidak dipilih kembali sebagai menteri maka tidak perlu memindahkan barang dari rumah dinas ke rumah pribadi kembali (Dwi \& Yahya, 1957).

Selama menjalani sebagai menteri, Ki Sarmidi mengeluarkan beberapa kebijakan yang membuat perubahan di Indonesia. Kebijakan yang dikeluarkannya yaitu Pemberantasan Buta Huruf (PBH), penetapan kalender akademik, pendidirian Akademi Seni Rupa Indonesia (ASRI) di Yogyakarta, penghargaan terhadap para pelajar pejuang revolusi, Undang-undang No. 4 Tahun 1950 tentang Pendidikan Nasional, sistem Universitas Gajah Mada, dan kebijakan lain (Chairunnisa dan Zulkarnain, 2018). Kebijakan Pemberantasan Buta Huruf ini dikeluarkan karena masih banyaknya rakyat Indonesia yang masih buta huruf sejak zaman penjajahan Belanda. Angka buta huruf masyarakat masih sangat tinggi. Dengan latar belakang dan pengalamannya di dunia pendidikan, Ki Sarmidi Mangunsarkoro sudah sangat mengerti apa kebijakan pendidikan yang ia harus ambil di tengah pembangunan negara yang sedang digalangkan pemerintah. Kegiatan PBH ini dilakukan dengan membuka kursus-kursus untuk masyarakat yang masih mengalami buta huruf.

Rencana kegiatan Pemberantasan Buta Huruf (PBH) di indonesia ini menghabiskan dalam waktu 10 tahu. Bukan waktu yang singkat untuk mengubah buta huruf yang dialami masyarakat Indonesia. Namun, pada kenyataannya cita-cita ini tidak tercapai dapat dilihat dari hasil sensus tahun 1971 yang menunjukan bahwa jumlah buta huruf di Indonesia masih mencapai 32, 21 juta atau kurang lebih 40\% masyarakat Indonesia masih mengalami buta huruf. Penyebab tidak tercapainya program PBH dipengaruhi oleh beberapa faktor. Walaupun jauh dari kata tercapai program $\mathrm{PBH}$ akan tetapi kebijakan Ki Sarmidi Mangunsarkoro tetaplah membawa dampak baik dan besar bagi pendidikan di Indonesia. kebijakan ini terus dilanjutkan dengan nama yang berbeda tetapi tujuannya tetap sama yaitu mengurangi angka buta huruf di Indonesia.

Selain mengeluarkan kebijakan PBH, Ki Sarmidi Mangunsarkoro juga mendirian Akademi Seni Rua Indonesia (ASRI) di Yogyakarta. Pendirian ASRI bertujuan untuk menjujung tinggi kebudayaan Indonesia dan mendidik pelajar menjadi warga negara yang berkebudayaan tinggi. Tentunya, kebudayaan yang ditanamkan adalah kebudayaan asli Indonesia. Akademi Seni Rupa Indonesia (ASRI) ini sejalan dengan pembanguna negara dalam sektor kebudayaan atau kultur karena pada tingkat pendidikan tinggi pengetahuan manusia dikembangkan sampai batas sistematika yang ada pada zamannya. Selain itu, pengetahuan atau ilmu yang dikembangkan di ASRI sangat beragam dan pasti akan berdampak terhadap bidang lain (Chairunnisa dan Zulkarnain, 2018).

Menteri PP dan K yang diembannya, Ki Sarmidi Mangunsarkoro memiliki pendirian dan prinsip teguh yaitu "Tidak mau bekerjasama dengan Belanda". Prinsip teguh yang dipegang itu memiliki makna bahwa belanda menggunakan kebudayaan lain yang sangat merugikan bangsa Indonesia. kebudayaan yang semestinya kebudayaan universal, tidak memandang bangsa, dan kerjasama merupakan hal yang baik tetapi Belanda merubah itu semua. Oleh sebab itu, ia menolak untuk kerjasama dengan Belanda. Selain itu, pernah 
pihak Belanda menawarkan buku-buku untuk Perpustakaan Negara kepada Ki Sarmidi Mangunsarkoro selaku Menteri PP dan K, tetapi ia menjawab tegas bahwa pihaknya akan menerima dengan catatan tanpa ada ikatan. Demikian pun apabila pihak Belanda memerlukan buku-buku dari RI akan diberi juga (Dwi \& Yahya, 1957).

Kebijakan penghargaan terhadap pelajar ini bertujuan agar dapat memotivasi pelajar tersebut. Para pelajar yang telah ikut berjuang dalam masa perang kemerdekaan antara tahun 1945-1950. Semangat penggerak persatuan pada masa kebangkitan nasional itu patut diberi penghargan. Tidak hanya masa revolusi, mereka juga tidak ketinggalan untuk ikut memanggul senjata (Chairunnisa dan Zulkarnain, 2018). Berkaitan dengan pendidikan, hasil hukum yang dapat dirumuskan yaitu Pengumuman Bersama Kementerian Pendidikan, Pengajaran, dan Kebudayaan (PP dan K) RIS dan Republik Indonesia (RI) pada 30 Juni 1950. Pihak RIS diwakili oleh J. Leimena dan RI diwakili oleh Ki Sarmidi Mangunsarkoro. Unsur pengumuman tersebut yang dihasilkan adalah upaya awal integrasi sistem dan sekolah-sekolah RIS ke dalam sistem RI terkait susunan sekolah-sekolah negeri dan swasta. Selanjutnya adalah Undang-Undang No. 4 Tahun 1950 tentang Dasar-Dasar Pendidikan dan Pengajaran di Sekolah (Edi Subkhan et al., 2018)

UU No. 4 Tahun 1950 tentang pendidikan nasional berdampak pada sektor politik ini dimaksudkan untuk menciptakan SDM yang cakap. Manusia yang cakap akan memperoleh dari suatu usaha yang teratur dan sistematis serta mengingat bahwa ia juga dinilai sebagai warga negara. Pengesahan UU No.4 Tahun 1950 ini disahkan oleh Ki Sarmidi Mangunsarkoro pada tahun 1950 saat dirinya menjabat sebagai menteri pendidikan (Guntur \& Zulkarnain, 2016).

Ki Sarmidi selaku Menteri PP dan K selain kebijakannya yang berhasil membuat dan mengesahkan Undang-undang (UU) Pendidikan dan Pengajaran. Ia juga berhasil meletakkan dasar-dasar atas kelahiran Universitas Gadjah Mada (UGM), terutama pada saat anggota dari The United Nations Technical Assistance Commissions yaitu Dr. Hatta Akrawi mengusulkan supaya Fakultas Kedokteran, Kedokteran Gigi, dan Farmasi dipindah dan digabungkan dengan Fakultas Kedokteran di Jakarta, pemindahan dan penggabungan itu dengan alasan di Yogyakarta sangat kekurangan dosen pengajar. Akan tetapi, pihak Senat di bawah pimpinan Dr. Sardjit yang didukung oleh Presiden RI Mr. Asaat saat itu dan Menteri PP dan K Ki Sarmidi Mangunsarkoro menolak dan tetap mempertahankan ketiga fakultas tersebut. Akhirnya, UGM lahir dengan Surat Keputusan yang ditandatangani Menteri PP dan K Ki Sarmidi Mangunsarkoro dan Presiden Mr. Asaat (Tarigan, 2013).

\section{KESIMPULAN}

Sejak penjajahan Belanda, perkembangan pendidikan di Indonesia masih di tingkat rendah. Hal itu dibuktikan oleh adanya kasus buta huruf yang terjadi di Indonesia. Minat baca masyarakat juga yang masih sangat minim sekali. Apabila tidak adanya pergerakan dari masyarakat pendidikan di Indonesia tidak akan berkembang dan stagnan sebagai kasus buta huruf yang tinggi. Oleh karena itu, lahir seorang penggerak bernama Ki Sarmidi Mangunsarkoro. Ki Sarmidi Mangunsarkoro lahir pada tanggal 23 Mei 1904 di Desa Banyuanyar, Colomadu, Surakarta, Jawa Tengah. Nama Mangunsarkoro yang terletak pada akhir namanya, yaitu diambil dari nama ayahnya Mangunsarkoro. Ki Sarmidi 
Mangunsarkoro merupakan anak ketiga dari lima bersaudara dari pasangan Mangunsarkoro dan Eyang Wiryo Didjojo.

Ki Sarmidi Mangunsarkoro dikenal sebagai penggagas perkembangan pendidikan di Indonesia. Dengan mempunyai latarbelakang di bidang pendidikan, membuatnya lebih semangat merubah pendidikan yang ada di Indonesia. Ada banyak hal yang telah diciptakannya bagi pendidikan bangsa Indonesia. Perjuangan besar untuk merubah pendidikan di Indonesia itu dibuktikan dengan kegigihan dan semangatnya. Hasil perjuangannya yang paling terkenal adalah Peguruan Taman Siswa Jakarta. Taman Siswa Jakarta merupakan tempat proses pendidikan cabang atau turunan dari Taman Siswa di Yogyakarta. Taman Siswa di Yogyakarta merupakan tempatnya mengabdi sebagai pengajar di sana. Gelar "Ki” yang didapat juga ketika ia mengajar disana.

Pembangunan Perguruan Taman Siswa Jakarta merupakan permintaan masyarakat kemayoran dan restu Ki Hajar Dewantara. Akhirnya, Ki Sarmidi memutuskan untuk mendirikan Perguruan Taman Siswa di Jakarta pada 14 juli 1929. Dana awal yang dikeluarkan untuk mendirikan perguruan ini sebesar 500 gulden. Perguruan ini terletak di Jalan Garuda No. 71 Kemayoran. Perkembangan Taman Siswa Jakarta membawa manfaat besar bagi masyarakat. Banyak sekali metode pengajaran yang diajarkan di perguruan ini. selain itu, wujud perjuangannya terhadap bidang pendidikan saat ia diangkat menjadi menteri. Ki Sarmidi Mangunsarkoro menggenggam jabatan Menteri Pendidikan itu dipangkunya pada periode kabinet Hatta yaitu Agustus 1949 - Januari 1950 dan pada periode kabinet Halim yaitu Januari 1950 - September 1950 bagi RI yang saat itu masih menjadi negara bagian Republik Indonesia Serikat (RIS).

Selama menjadi Menteri PP \& K, ia banyak mengeluarkan kebijakan-kebijakan. Kebijakan yang dikeluarkannya yaitu Pemberantasan Buta Huruf (PBH), penetapan kalender akademik, pendidirian Akademi Seni Rupa Indonesia (ASRI) di Yogyakarta, penghargaan terhadap para pelajar pejuang revolusi, Undang-undang No. 4 Tahun 1950 tentang Pendidikan Nasional, sistem Universitas Gajah Mada, dan kebijakan lain. Oleh karena itu, ia dikenal sebagai salah satu pejuang pendidikan di Indonesia.

\section{REFERENSI}

Anisah, N. U. R., Tarbiyah, F., Ilmu, D. A. N., Pendidikan, J., \& Islam, A. 2015. Pendidikan karakter dalam perspektif ki hajar dewantara skripsi. dan Zulkarnain, C. (n.d.). Kebijakan Pendidikan Di Indonesia Pada Masa Menteri Sarmidi Mangunsarkoro (1949-1950) Educational Policy In Indonesia During Minister Sarmidi Mangunsarkoro Era (1949-1950).

Dwi, P., \& Yahya, R. 1957. Peranan Ki Sarmidi Mangunsarkoro Dalam Bidang Pendidikan Tahun 1926-1957. May 1904.

Iii, B. A. B. 2005. Verry Hendra S.R, 2012 Suatu Kajian Tentang Sosialisasi UU No 22 Tahun 2009 Tentang Lalu Lintas dan Angkutan Jalan Guna Menignkatkan Kesadaran Hukum Masyarakat dalam Berlalulintas Universitas Pendidikan Indonesia | repository.upi.edu. 22, 48-57. Pemikiran Sri Wulandari Mangunsarkoro Tentang Pendidikan Dan Wanita (1923-1959). (n.d.). 
Pengaruhnya, D. A. N., Arah, P., \& Indonesia, P. N. 2018. Ideologi, Kekuasaan, Dan Pengaruhnya Pada Arah Sistem Pendidikan Nasional Indonesia (1950-1965). Journal of Indonesian History, 7(1), 19-34. penyelenggaraan pendidikan kesenian dalam rangka menumbuhkan budi pekerti di perguruan tamansiswa yogyakarta tahun 1922-1942. (n.d.).

psikologi, d. f., \& jaya, u. a. (2016). gambaran pendidikan kepemimpinan melalui metode “ among" di perguruan tamansiswa. 14, 101-112.

Tarigan, P. B. 2013. Menteri Pendidikan dan Kebudayaan Republik Indonesia 1945-2018. In Journal of Chemical Information and Modeling (Vol. 53, Issue 9). https://doi.org/10.1017/CBO9781107415324.004

Widada, Rh. 2013. Guru Patriot: Ki Sarmidi Mangunsarkoro. Yogyakarta: Ar-Ruzz Media. 